\title{
Comunicación e identidades del baile
}

\section{Un breve acercamiento a la etnografía de la salsa en una salsoteca de Quito}

Gabriela Paz

pazitavida@gmail.com

\section{Resumen}

El presente trabajo indaga sobre la salsa en su dimensión sociocultural y como práctica performática. Explora el baile de salsa como construcción de sentidos en Quito, y la actuación de los sujetos que la practican y que llegan a componer una comunidad que se autoidentifica como "salseros". Aborda además, desde un ejercicio etnográfico, la experiencia social del bailar salsa en un espacio específico y, por esta vía, identifica las diversas formas de comunicación que inciden sobre la construcción de la identidad y que son el fundamento del mundo simbólico de sus practicantes.

Palabras clave: etnografía, salsa, baile, estéticas, performance, cuerpo, identidades

\begin{abstract}
This article explores salsa in its sociocultural dimension and as performative practice. It explores salsa dancing as a construction of senses in Quito, and the performance of the subjects who practice it and who come to compose a community that identifies itself as "salseros". Besides, from an ethnographic exercise, the social experience of salsa dancing in a specific space and, identifies the different forms of communication that affect the construction of identity and that are the foundation of the symbolic world of its practitioners.
\end{abstract}

Keywords: ethnography, salsa, dance, aesthetics, performance, body, identities 


\section{Introducción}

Este trabajo es un esfuerzo por aportar a la práctica etnográfica, es decir, realizar un registro de observación y profundidad de un entorno, como objeto de estudio, que se observa con fines investigativos. La etnografía es una puerta de entrada hacia la comprensión de la alteridad y el descubrimiento de lo distinto, es un registro de flujos de la vida diaria. Jesús Galindo Cáceres sostiene que "la etnografía tiene una vocación del otro, lo busca, lo sigue, lo contempla."' La presente etnografía examina, desde los Estudios Culturales (y de ciudad), algunos aspectos sobre lo que significa "vivir la urbe" y su significación social, es decir, desde quienes habitan la ciudad nocturna, sus ritos, ritmos, espacios de encuentro y socialidad.

Este estudio indaga el fenómeno cultural de las diferentes expresiones contemporáneas de la salsa en Quito. Así, tiene como meta acercarse al ocio y al entretenimiento, y a esas otras formas de apropiación y de construcción de lo urbano: la "farra" y ciertas formas de divertimento colectivo. Dado que la investigación es etnográfica, se trata de aproximarse a los análisis de las prácticas corporales/musicales que son traducidas como "baile" y de pensar la comunicación.

Se desea aprehender las lógicas estructurales y dinámicas procesuales referidas a la corporalidad de quienes bailan y de quienes escuchan salsa. Dentro de la corporalidad, hay algo que se llama "sonoridad musical", actuada como una práctica de escucha que acompaña al ritmo o que puede devenir en una práctica de "corporalidad en movimiento", la cual cuenta con reglas propias.

Se hace un breve acercamiento sobre la descripción de los rituales de la salsa, en el espacio escogido desde una aproximación basada en la teoría del performance que aborda igualmente a las estéticas y los procesos de identificación y de construcción identitaria desde el cuerpo en escena, es decir, desde la representación y cómo se presentan los cuerpos en movimiento. En este mismo sentido, se aborda las dimensiones estéticas presentes en las formas que se recrean en las prácticas salseras y cómo, a partir de estas, se producen las identificaciones colectivas y los rasgos de comunalidad entre los participantes. Esta investigación está

1 Jesús Galindo Cáceres, Técnicas de investigación en sociedad, cultura y comunicación (CDMX: Addison Wesley Longman, 1998), 347. 
enriquecida con relatos de algunos de los actores del lugar que se observa como DJ, melómanos, bailarines, músicos e intérpretes.

\section{El baile como performance}

El presente trabajo tiene como fin acercarse a la representación corporal mediante el baile, dentro de un contexto específico como es Salsoteca Lavoe, y a las diferentes formas de construcción de la subjetividad en escena desde tres dimensiones principales: las performativas, las estéticas y las identitarias.

Para esto, es necesario hacer una aproximación al performance entendido como puesta en escena como un espectáculo (representación en el sentido de realización). Y, a su vez, a la representación como la construcción lúdico-ritual de la corporalidad en escena, que asimismo comprende un mundo lleno de significados y sentidos. Dentro de este contexto, se puede considerar el baile como performance, como acciones que dotan de sentido a esta práctica.

Este abordaje conceptual proviene de los llamados estudios de la representación, también conocidos en su versión anglosajona como "estudios de performance". La categoría de representación hace referencia a la reflexión políticocultural de Stuart Hall, desde un punto de vista semiótico. Para la aproximación al performance se tomará en cuenta las teorizaciones de Érika Fischer-Lichte ${ }^{2}$ y de Richard Schechner ${ }^{3}$ que marcan un sentido teatral o dramatúrgico, y lo delimitan desde la interacción escénica. En ambos casos, y de una manera complementaria, el objetivo es dar cuenta de las prácticas salseras como "acciones con significación" y así acercarnos a los procesos de construcción identitaria de sus actores.

Respecto a la "representación", Stuart Hall precisa la noción de reconocimiento: "[E]s el vínculo entre los conceptos y el lenguaje el que nos capacita para referirnos sea al mundo 'real' de los objetos, gente o evento, o aun a los mundos imaginarios de los objetos, gente y eventos ficticios". ${ }^{4}$ Enfatiza que se trata de

2 ÉrikaFischer-Lichte, Estética de lo performativo (Madrid: Abada, 2011).

3 RichardSchechner, Performance Theory (Londres: Routledge, 2004).

4 Stuart Hall, ed., Representation: Cultural Representations and Signifying Practices (Londres: Sage Publications, 1997). Se cita la traducción de Elías Sevilla Casas en versión electrónica. http://fba.unlp.edu.ar/lenguajemm/?wpfb_dl=31 
simbolizar algo, es decir, dotar de sentido a los conceptos mediante el lenguaje y sus prácticas.

Para Hall, en la sociedad, el sistema de representación consiste en la conexión significante de los sentidos del lenguaje y la cultura; se trata de "decir algo con sentido", 5 lo que se expresa permanente y cotidianamente en la vida social de los individuos. Son formas de decir y expresar, de comunicarse y que los otros lo entiendan sin que ese sentido se pierda. Lo que aquí interesa es explicar cómo se interpreta el mundo desde la representación, ya sea esta individual o colectiva, y dentro del escenario o lugar, objeto de estudio. Dado que esta investigación gira en torno a la dimensión comunicacional, política y cultural de ciertas prácticas de baile que a su vez implican una desbordada actividad estético-placentera, lúdico-ritual, se hará referencia a la comunicación como interacción a la vez que como proceso y cómo esto tiene que ver con lo representacional, es decir, con lo simbólico.

Cada uno de nosotros entiende e interpreta el mundo de una manera única e individual. Sin embargo, somos capaces de comunicarnos porque compartimos de manera amplia los mismos mapas conceptuales y porque interpretamos el mundo, o le damos sentido, aproximadamente de la misma manera. Esto es lo que de hecho entendemos cuando decimos que "pertenecemos a la misma cultura". Porque interpretamos el mundo de manera aproximadamente igual, podemos construir una cultura compartida y de sentidos, y por tanto construir un mundo social que habitamos conjuntamente. ${ }^{6}$

Para Hall, las prácticas de representación se anclan en los procesos de construcción del sentido (desde el sonido, la palabra, las imágenes, objetos y acciones que funcionen como signo) y mediante el lenguaje o "lenguajes". La representación corporal adopta la forma de baile y se torna constitutiva de un sistema de representación que, en este caso, se puede comprender como un performance lúdico. Hall explica que "somos nosotros los que fijamos el sentido de manera tan firme que, después de cierto tiempo, parece ser una cosa natural e inevitable. El sentido es construido por el sistema de representación y fijado por un

5 Ibíd., 2

6 Ibíd., 5. 
código, que establece una correlación entre nuestro sistema conceptual y nuestro sistema de lenguaje".?

De su parte, Érika Fischer-Lichte plantea la actuación escénica como el lugar para pensar la comunicación, con lo cual se puede entender desde otra perspectiva al "humano-actor" para explicar lo que ocurre en la representación. El término "representación" remite a una realidad previa que se vuelve a hacer presente por medio de una mediación material, como la palabra o la imagen, organizada por medio de unos códigos. ${ }^{8}$

Por otro lado, la representación implica siempre una accionalidad social dotada de materialidad y formas concretas, en la cual coexisten elementos como la sonoridad, el espacio y la expresividad corporal que se integra dentro de un solo contexto. Un performance alude a una "puesta en escena" y así, en este lugar teatral, se detonan acciones dramatúrgicas de carácter teatral. La vida cotidiana de las personas expresa siempre una continuidad de "quehaceres" y actuaciones, las cuales se escenifican en un espacio y en un tiempo determinado, producidos y contextualizados socialmente.

En este sentido, Richard Schechner sostiene que, si bien casi cualquier situación social puede ser estudiada como representación, los rituales, los roles y los juegos de la vida cotidiana son fenómenos socioculturales muy importantes en cada contexto social y cultural, pues posibilitan diferentes interpretaciones sociales de gran peso. La cotidianidad trata de acciones y movimientos que se repiten, pero que, por su carácter polisémico, producen cada vez significaciones distintas. Pese a ser actos repetitivos, son estéticas distintas y así esta constante reproducción de movimientos y actuaciones puede estar cargada de significaciones rutinarias entre los actores. Schechner plantea que: "La vida cotidiana está construida por repeticiones. [...] cada acción, desde la más pequeña hasta la más englobante, está hecha de conductas realizadas dos veces. Honrar lo ordinario es darse cuenta de cuán

7 Ibíd., 7.

8 Fischer-Lichte,Estética de lo performativo, 17. 
ritualística es la vida diaria, y a qué grado la vida cotidiana está construida por repeticiones"'.

El baile es un acto no solo gozoso, sino de repeticiones reiteradas, se repiten las canciones, se repiten los pasos, las parejas: "Me gusta bailar con Billy "agua que va a caer', de Tromboranga. Sin importar cuántas veces la pongan, siempre voy a bailar con él esa canción". 10

Acciones y comportamientos en escena: eso es la representación. En este caso, desde el baile, cada canción puede tener los mismos actores o los mismos movimientos, pero producen sentidos distintos en el ámbito subjetivo e intersubjetivo. Es importante señalar que ciertas representaciones de corte teatral son instantáneas y breves, por ese motivo parecen siempre sorprendernos. Érica Fischer-Lichte afirma que "la fugacidad de las realizaciones escénicas no es un artefacto material fijable ni transmisible, sino que son fugaces, transitorias y se agotan en su propia actualidad, es decir, en su continuo devenir y desvanecerse. La realización escénica se pierde al terminar y no se puede repetir nunca de forma idéntica. ${ }^{1}$ Prueba de ello es que la entrevistada anónima siente diferente cada vez que baila con la misma persona (Billy), cada ocasión es única e irrepetible aunque la canción, el lugar y el bailarín sean los mismos siempre.

Otra característica de estas acciones performáticas es que algunas tienen un efecto conativo: pueden actuar como prácticas de expresión ante los demás y de entretenimiento con ellos, por lo que actúan como formas de darse a conocer, de re-conocer y de sentir placer. De acuerdo al contexto, existe una combinación entre el propósito expresivo de la representación, tal como "hacer alarde" de habilidades corporales, a la vez que pasar el tiempo placenteramente. En el caso aquí analizado, la representación es sobre todo, aunque no exclusivamente, entretenimiento. ${ }^{12}$

Mi experiencia en la salsa y en el baile me dice que no importa en gran medida si la pareja sabe bailar o si sabe todos los pasos, porque, en la salsoteca, nadie está en competencia; en realidad, lo que a mí me importa,

9 Richard Schechner, Estudios de la representación: una introducción (México, Fondo de Cultura Económica, 2012), 60 .

10 Anónima (la entrevistada pidió reservar su identidad), entrevista realizada el 10 de junio de 2015.

11 Fischer-Lichte, Estética de lo performativo, 155-6.

12 Schechner, Estudios de la representación, 137. 
cuando bailo e invito a bailar, es que ese baile sea de goce, de disfrute, para mí el mejor paso de baile en la salsa es la sonrisa, siempre les digo "solo goce".13

"La interacción de los cuerpos y el movimiento en el espacio ponen en escena códigos, sensibilidades y gestos que conforman un lenguaje con el cual el cuerpo también habla". ${ }^{4}$ Dada la brevedad de los encuentros durante el baile, se dirá, entonces, que son sensaciones fugaces, entendidas como la base de esta "otra" forma de comunicación, la comunicación entre los cuerpos.

Por su parte, la música cumple doble función: por un lado, alude a un mundo simbólico (como música de fondo), y a la vez, es la que marca los movimientos corporales, es decir, es la pauta de los comportamientos sociales.

En este contexto cultural, el baile significa tanto más placer cuanto más conlleva un efecto estético intensificado. Zandra Pedraza manifiesta que el placer "es el móvil de las acciones humanas, es el goce sensorial, equivalente al goce carnal". Para esto hace referencia a las "hiperestesias" o "sentividad" como el "anhelo de sensaciones intensas, instantes extáticos, arrebatos y espasmos sensoriales, organizadas por medio del refinamiento de percepciones". ${ }^{15}$ El baile eleva el nivel de adrenalina, el cuerpo queda excitado; es decir, abarca niveles perceptivos, sensoriales, táctiles, auditivos, de movimientos, visuales y aquí es pertinente mencionar que existe una dimensión hiperestésica en el baile.

Al respecto, Pedraza asegura que:

La experiencia de sentir corporalmente la vida y la certeza de que el bienestar consiste en buena parte en preparar y perfeccionar la capacidad sensorial -en educar los sentidos- para captar la mayor cantidad de estímulos, diferenciarlos en sus más detalladas minucias, hacerlo con mayor intensidad que nos sea dado experimentar, la autocomplacencia en la sensitividad, la entrega total a ese mundo interno... el cuerpo moderno se explaya a gusto en estas dimensiones. ${ }^{16}$

13 Diego Vega, entrevista realizada el 7 de junio de 2013.

14 Schechner, Estudios de la representación, 125.

15 Zandra Pedraza, En cuerpo y alma: Visiones del cuerpo y de la felicidad (Bogotá: Universidad de los Andes, 1999), 274.

16 Ibíd., 271. 
Para Pedraza, los sentidos confluyen en el campo de la corporalidad, que a su vez están ancladas en las percepciones y las construcciones estéticas, las cuales se deben leer como un solo conjunto. Cuando se baila, se establece un campo de interacción con el otro, el primer encuentro es físico, es muy del cuerpo y, después, se establece un vínculo en el campo de lo simbólico, se establece una conexión. En este sentido, David Le Breton asegura que el tacto viene a jugar un papel protagónico, pues es desde donde se marca las pautas del sentido de esa conexión durante el baile. "El tacto es el sentido inicial del encuentro. Se tiene el sentido del tacto, se sienten las cosas gracias a una sensibilidad a flor de piel". ${ }^{17}$

El hecho de "sentir" el baile remite simultáneamente a la percepción táctil y a la esfera de los sentimientos, incluso el divertimento. ${ }^{18}$ El cuerpo es lugar de goces, recipiente sensorial y emotivo. Se trata de una apropiación corporal en relación de alteridad, es decir, existe un nivel de apropiación del cuerpo del "otro". Manuel Delgado, desarrolla aún más el planteamiento de sobre el cuerpo y la "apropiación"en el sentido que "el cuerpo amante no coloniza ni invade el cuerpo amado, sino que se apropia de él, en tanto que obtiene de él sensaciones que devuelve". 19 Esta analogía en cuanto al cuerpo se puede reflejar también en el campo del baile cuando se escoge una pareja para bailar.

Alejandro Ulloa sostiene que el baile es un acontecimiento efímero dentro de un mar de flujos, movilidades y fugacidades; un "sentir" que, en la salsa, "dura lo que dura una canción". Salsoteca Lavoe es un lugar donde la música marca las pautas que direccionan conductas predeterminadas de estos cuerpos, es un espacio de construcción de sentidos, de lenguajes, de comunicación.

Según Ulloa, el baile, como un lenguaje corporal, no necesita de la oralidad; y se trata fundamentalmente de un lenguaje entre "cuerpos que hablan" y, como en todo diálogo, se sigue un modelo conversacional, de turnos y secuencias, acciones que conforman códigos que materializan el performance corporal. ${ }^{20}$

17 David Le Breton, El sabor del mundo: Una antropología de los sentidos (Buenos Aires: Nueva Visión, 2007), 179.

18 Ibíd., 179

19 Manuel Delgado,Disoluciones urbanas (Medellín: Universidad de Antioquia, 2002), 126.

20 Alejandro Ulloa, El baile: un lenguaje del cuerpo (Cali: Secretaría de Cultura y Turismo, Gobernación del Valle del Cauca, 2003), 140. 
Soy ecuatoriano, bailo salsa y vine a Suecia a estudiar, y, en menos de un mes, ya me incorporé a esta cultura a través del baile, no en un $100 \%$ porque tengo mis procesos, pero me ha ayudado muchísimo, mis amigos que no bailan se han demorado casi dos años. Es que donde sea que estés, vas a un lugar de salsa y la gente que te mira ya sabe que no eres de ahí, como cuando vemos un foráneo en Lavoe, y se hacen amigos y entras al círculo de la salsa. Es como que te sientes en casa, es decir, no tan lejos. Las culturas en todo el mundo son diferentes, pero, en la salsa, la cultura es una sola o por lo menos se parece mucho. Siempre es más fácil conocer gente de otras culturas y descubrir que se tiene algo en común como base, no es tan duro el proceso de acoplamiento en los lugares no tan familiares. ${ }^{21}$

Así, el bailar salsa, puede ser considerado un mecanismo de producción de sentidos y una forma de identificación social, un vehículo de adaptación a esa idea de lo social a partir del cuerpo y de comprensión de determinados códigos culturales.

De acuerdo a Ulloa, "saber bailar" salsa es como saber manejar un lenguaje o un "habla", es tener destrezas para utilizar ese lenguaje, pero no hay que olvidar que, en este espacio, como ya se explicó anteriormente, también existen personas no diestras que constituyen y forman parte del lugar, perose puede observar que, al bailar en Salsoteca Lavoe, la mayor parte de personas llevan a cabo un proceso de identificación entre iguales.

Ulloa menciona cómo el baile activa todo el cuerpo, práctica en la que se destaca el predominio de unas partes corporales sobre otras. Sin embargo, el desconocimiento y la falta de dominio de las "técnicas corporales" o sobre los pasos coreográficos rompen la armonía del baile, lo que genera efectos de desidentificación con los que "no saben", aunque en ocasiones y dentro de la lógica de la noche salsera estos obstáculos se pueden disolver:

En las parejas donde uno de los dos no es un buen bailador, o no sabe bailar salsa, el desencuentro de los pies se percibe claramente desde el inicio. Aunque los buenos bailadores suelen superar este impasse rápidamente. Quien no se acopla en la alternancia de los pies puede quedar en evidencia como alguien que no sabe bailar. Este hecho tiene fuertes implicaciones

21 Carlos Gustavo Arellano, salsero, entrevista realizada el 13 de octubre de 2013. 
simbólicas y sociales allí donde hay una cultura del baile, es decir, donde este está altamente codificado como un lenguaje. ${ }^{22}$

Durante esta investigación, se observó que, en el espacio donde se aprecia una experticia del cuerpo y, en este caso, del baile, aquellos que no bailan se sientan que los que sí bailan los van a juzgar y, de alguna manera, se intimidan y opacan; esto hace que construyan mecanismos de defensa ante ese sentimiento dentro de este escenario. Se registraron patrones de conducta "en manada", es decir, "juntos somos invencibles", ¿ cómo lo hacen? Todos juntos salen a la pista, abren una bomba casi impenetrable y bailan con una suerte de teflón "antivergüenzas" ya que sienten que juntos nadie los va a mirar y así no se pone en evidencia el hecho de no saber bailar como la mayoría, que son de escuela o que tienen años de experiencia en las pistas, es decir, crean su propio código de identificación. Pero eso no significa que no gocen del ambiente del lugar.

La música, el baile, y más específicamente la salsa, son un espacio de expresividad, que se lleva a cabo entre personas que comparten los mismos escenarios y que utilizan esos lugares que habitan como plataformas de la comunicación. En las entrevistas que se realizaron, se notó que muchos de los músicos que son salseros y que asisten a este lugar no necesariamente saben bailar; no es una regla, pero gozan de manera distinta. Ya que en el lugar existen muchos instrumentos de percusión disponibles para el público, los músicos eligen un instrumento y lo tocan mientras bailan solos (o acompañados a modo de orquesta improvisada y lúdica).

Soy música y cantante profesional.Cuando voy a la salsoteca, cojo el güiro y canto, soy percutiva ${ }^{23}$ y eurítmic ${ }^{24}$, voy sola y me gusta bailar sola porque yo me entiendo, el baile en pareja implica dejarse llevar y una conexión con la otra persona, la cosa es que yo me conecto mejor con los instrumentos, prefiero bailar con mi güiro, él activa mi ritmo interno, me hace tener la noción de la clave para no perderme. En esta sociedad machista, en mi campo, persiste un imaginario de que las mujeres que cantamos no sabemos tocar instrumentos musicales y mucho menos de percusión, ya que el golpe de la clave es, en su mayoría, una práctica masculina, pero yo canto, toco y bailo. Ah, también, soy también bongocera ${ }^{25} .26$

22 Ulloa, El baile: un lenguaje del cuerpo, 142.

23 Percutiva/o, es hacer del propio cuerpo un instrumento de percusión.

24 Se trata de hacer percusión con el propio cuerpo y a la vez cantar.

25 Que toca el bongó.

26 Cindy Miranda, cantante y música profesional, entrevista realizada el 2 de junio de 2015. 
Por medio de estos testimonios, se logra visibilizar cómo los sujetos tienen sus propios ritmos y formas de goce dentro de un mismo lugar.A cada uno le asiste un sentimiento distinto con lo cual van construyendo su noche, su mundo simbólico y su vida, es eso lo que los hace volver cada vez.

\section{Socialidades e identidades salseras}

Durante el trabajo de campo de esta investigación, se encontró que existen personas que tienen rutinas diversas en estos espacios de prácticas salseras: unos bailan todos los días o por lo menos cuatro días a la semana y no conciben su vida sin el baile dentro de su quehacer diario; otros van a bailar eventualmente. Estas diferentes rutinas marcan diversas socialidades o maneras de "estar juntos", puesto que, según Maffesoli, "lo ritual proclama el retorno de lo mismo. Más concretamente, mediante la multiplicidad de los gestos rutinarios o cotidianos, el ritual recuerda a la comunidad que 'forma cuerpo'. Sin necesidad ninguna de verbalizarse, sirve de anamnesis de la solidaridad. La costumbre es lo que funda el estar juntos". ${ }^{27}$

Por lo tanto, el cuerpo en movimiento y la fugacidad del contacto, implica que, desde "la presentación, se regresa laboriosamente sobre la misma cosa, es la necesidad de la contemplación que permite captar la multiplicidad de sentidos de un mismo objeto, sus ritmos variados, en una palabra toda su concretud". 28 Es así que también hace referencia al "estar juntos", a lo cual Maffesoli llama 'socialidad', entendiéndola como una forma lúdica de socialización. En este sentido, "la salsa, es una práctica social de carácter lúdico que se realiza a partir de unos códigos configurados culturalmente, los cuales es necesario aprender para poder interactuar con los demás." 29 Esta socialidad es la que hace posible que el acto o situación configurados por una pareja bailando se la entienda como una unidad.

El autor plantea que toda esta problemática está basada en la "cuestión estética" y para esto hace referencia a la "artrología", es decir, "el estudio de las articulaciones, de los vínculos, de las relaciones sociales [...].La artrología permite la

27 Michel Maffesoli, El tiempo de las tribus (CDMX:Siglo XXI, 2004), 46.

28 Michel Maffesoli, En el crisol de las apariencias: Para una ética de la estética (CDMX: Siglo XXI, 2007), 96.

29 Ulloa, El baile, 136. 
función esencial de la estética". ${ }^{30}$ En este sentido, ya que este estudio centra su atención en la salsa y las representaciones del propio baile, se trata de explicar un escenario compuesto de formas corpo-significantes que están actuando; la forma de la salsa se trata del actuar de los cuerpos que van construyendo identidades que tienen sentido en escenarios específicos.

Por tanto, para potenciar la noción de identificación alrededor del lugar que se habita, Maffesoli expone la categoría de "territorio flotante" como los lugares de la vida social que no pertenecen a ningún lugar ya que "la vida es un andar de aquí para allá". El autor explica que el deseo de los sujetos sociales siempre está anclado a la idea de la movilidad como sinónimo de vida, siempre en contra de "la quietud de la muerte" y que vivir en estos lugares durante horas, momentos o etapas es como "disfrazar la inmovilidad", se trata de lugares mentales, cargados de representación con peso simbólico; es decir, la salsoteca tiene una existencia material real, pero sin las prácticas socioculturales desplegadas alrededor de la música, sin las personas que la habitan, eso no representa nada.Por ejemplo, duranteel día, el lugar está cerrado, está vacío.

La realidad en sí no es más que una ilusión, siempre flotante, y no puede ser aprehendida más que en su perpetuo devenir. Aun siendo necesario, el territorio es relativo. [...]. En su sentido más fuerte, ese espacio urbano, concentrado en la ciudad, abreviación del mundo, es sin duda alguna un crisol: lugar en el que se echan raíces y a partir del cual se crece y se evade. Lugar en el que se expresa la empatía con los demás, lugar donde se escapa, imaginariamente, para alcanzar la alteridad absoluta. ${ }^{31}$

Al respecto, Manuel Delgado sugiere que los espacios públicos son desterritorializados y están en una constante e infinita reterritorialización, ya sea por la concurrencia, el aglomeramiento y las diferentes prácticas sociales que se producen en ellos. Asimismo explica cómo, desde los espacios públicos, la sociedad se organiza, apropia y construye desde la similitud y la alteridad, las diferentes formas

30 Maffesoli, En el crisol de las apariencias, 111.

31 Michel Maffesoli, El nomadismo: Vagabundeos iniciáticos (CDMX: FCE, 2004), 92-4. 
de socialidad y encuentro y de cómo las interacciones son una forma compleja de cohesión social.

Sobre esta dinámica, es preciso hacer nuevamente referencia a la estética. Maffesoli explica que todo aquello que despierta la sensibilidad, las sensaciones, los sentimientos y las atracciones forma parte del mundo de la estética. El autor considera que la estética social se organiza alrededor de cuatro ejes: la prevalencia de lo sensible, la importancia del entorno o del espacio, la búsqueda del estilo y la valorización del sentimiento tribal.

\section{La dimensión estética del baile}

La música es un elemento complejo para ser analizado, teóricamente, por su polisemia, pues pone en funcionamiento la subjetividad de las personas, además de que produce un mundo afectivo. Adicionalmente, Rubén López sostiene que

La música está estrechamente vinculada a los sentimientos, los cuales, si bien están contextualizados socialmente, son fundamentalmente individuales y están anclados en nuestros propios cuerpos de manera particular. La música es algo que se 'posee' y, al generar sentimientos de pertenencia sobre un determinado género, la convertimos en parte de nuestra propia identidad y la incorporamos a la percepción de nosotros mismos. 32

De eso tratan las prácticas predominantemente estéticas: generan distintas percepciones, sensaciones y sentimientos: alegría, euforia, sensación de plenitud, disfrute sensorial, es decir, lo que las personas "sienten" cuando bailan salsa. Esta dimensión apunta a lo lúdico, a la dimensión placentera y deseante del ser humano.

Es fácil comprender una manifestación privilegiada de la estética en el sentido preciso que se da al término: el de experimentar vivencias juntos, participar en el mismo ambiente, comulgar con los mismos valores, perderse, en fin, en una

32 Rubén López, "La salsa en disputa: Apropiación, propiedad intelectual, origen e identidad",Etno-folk. Revista de Etnomusicología 14-15 (2009), versión electrónica disponible en http://www.academia.edu/6952598/La_salsa_en_disputa._Apropiaci\%C3\%B3n_propiedad_intelectual_orig en_e_identidad,6. 
teatralidad general, permitiendo así que tengan sentido estos elementos que constituyen la superficie de las cosas y de las personas. ${ }^{33}$

Jesús Martin Barbero indica que "el hacer estético, es lo que a su vez revela el paso de la primacía sensorio-motriz a la sensorio-simbólica". ${ }^{34}$ Se trata de explicar cómo, en ciertos espacios de baile, se activa un campo simbólico y estético de los cuerpos que sienten (actividad sensorial). La música es el componente imprescindible para detonar las actividades vinculadas con la socialidad, es decir, de las formas contemporáneas de juntarse, de los nuevos modos de vida, de esta unión, se despliega el aura estética o la Aesthetica, es decir, el placer de los sentidos experimentados en común. ${ }^{35}$ Se refieren a la facultad de usar ciertas técnicas corporales dentro del baile (miradas, gestos, giros, vueltas, cargadas) con el fin de sentir y experimentar en conjunto, pero también es un"medio para reconocerse"o identificarse como parte de un grupo social.

Maffesoli también se refiere a las emociones colectivas que se expresan por intermedio de las características que el autor llama "paradigma estético" que se construye alrededor del sentir en común, quiere decir que la validez de la persona viene dada en tanto se relaciona con otros y cómo los siente.

La emoción colectiva es una cosa encarnada, una cosa que se alimenta de ese conjunto de facetas de la sensibilidad colectiva, de una memoria colectiva. [...]la sensibilidad colectiva al superar la autonomización individual, crea las condiciones de posibilidad de una especie de "aura"que va a especificar a tal o cual época; y es posible que estemos asistiendo a la elaboración de un "aura"estética, en la que se encontrarían, en proporciones diversas, elementos que remiten a la pulsión comunitaria que daría cuenta de la organicidad de las cosas, de ese glutinum mundi que hace que, pese a 0 causa de la diversidad, tome cuerpo un conjunto. ${ }^{36}$

Bailar salsa es una forma de experimentar estos sentidos, de eso se trata la estética de la salsa, e incluso esta podría ser una causa mayor del porqué conviven personas con los mismos gustos alrededor de los espacios de escucha y de baile

33 Maffesoli, En el crisol de las apariencias, 126.

34 Jesús Martín Barbero,"Tecnicidades, identidades, alteridades: Des-ubicaciones y opacidades de la comunicación en el nuevo siglo",Diálogosde la Comunicación 64 (2002), 12-13.

35 Maffesoli, En el crisol de las apariencias, 55.

36 Maffesoli,El tiempo de las tribus, 40-1. 
salseros, ya que estas se reúnen cotidianamente en los mismos lugares, a hacer las mismas cosas, a realizar los mismos movimientos y escuchar la misma música una y otra vez, cada semana.

Este espacio se justifica en referencia a que los bailarines se comunican entre sí mediante la construcción de significados con sus cuerpos; a la vez, esos significados son el puente entre el cuerpo y la identidad del sujeto (que no son separables) y con ese puente se entiende el conjunto como una sola cosa.

Es mediante el baile que se juntan y se entienden los sujetos, es decir, con estos lugares de identificación, donde al mismo tiempo pueden reproducir o transgredir normas o roles sociales. Respecto a esto último, en Lavoe se rompen los clásicos roles de género, por ejemplo, cuando las mujeres sacan a bailar a los hombres "Una de las cosas más lindas de la salsa y de Lavoe es que las mujeres no esperan nada: ellas toman la iniciativa y te sacan a bailar" 37 o cuando dos mujeres bailan juntas. En este escenario, desde el baile, se transgrede roles tradicionales de género que, en la sociedad, son dominantes, eso es identidad, la construcción de sentidos.

Tradicionalmente, en la salsa se supone que el hombre lleva y la mujer se deja llevar, pero son pautas modificables, ya que dos mujeres pueden bailar juntas, en este caso una persona lleva y la otra le sigue; también existen momentos en que se baila entre dos hombres, dos mujeres, tríos y grupos (rueda de casino o salsa urbana), por lo tanto, se marca una experiencia diferente entre géneros "en Lavoe, no hay hombres y mujeres bailando, hay personas felices y sin etiquetas, solo están bailando, están sintiendo".38

\section{Comunalidades y señas de identidad particulares}

Existe una identidad genérica común y un espacio alrededor de la salsa ("somos salseros"), pero también hay formas particulares para practicarla y ser parte de microcomunidades. En este contexto, desde los diferentes estilos de baile ("línea", "caleño" o"cubano/casino") se observa la primacía de unas formas sobre otras, desde los mismos cuerpos. Se trata de la ruptura de la forma tradicional de concebir el baile como un performance de enlazamiento hombre/mujer y pensarlo como una

37 Leandro Villacís, bailador, entrevista realizada el 7 de febrero de 2015.

38 David Guerra, bailador, entrevista realizada 12 de enero de 2015. 
relación de empatía entre géneros y de permanente construcción de identidades grupales, es decir, cambia la forma y se concibe una nueva o diferente.

Entonces, el baile aparece como un mundo de formas que compone el fondo de las estéticas. "La existencia social solo existe cuando se deja ver, y cuando toma forma. Y esta forma tiene características teatrales. El theatrum mundi no es un concepto vano; su expresión es multiforme (política, económica, cotidiana...) seguramente eso avala la reflexión sociológica sobre el 'formismo'".39El baile también es una forma de concebir el mundo, tanto de salseros como de no salseros; el baile, en cualquier forma o estilo, es parte de las culturas o de las formas culturales de sus habitantes.

Durante la investigación, se dejaron ver, en un primer momento, las formas visibles desde el baile; $y$, en un segundo momento, fueron emergiendo las formas de socialidad y encuentro, como parte del proceso de aguzamiento de la mirada del observador: ir de lo material y visible a lo social y simbólico.

El mundo está hecho de formas, las personas se comunican por intermedio de ellas y mediante el uso de lenguajes (orales, escriturales y corporales). De esta manera, el idioma compartido se convierte en un elemento configurador de la identidad. La "forma" es la actuación másel significado. A este respecto, Michel Maffesoli expone el "formismo" 40 como una categoría sociológica para entender la compleja y dinámica constitución del mundo, plural y diverso. La "forma" es la mediación entre el yo y el mundo natural y social". ${ }^{41}$ Es decir, este juego de las formas mantiene activos los procesos de comunicación en un universo simbólico que producen sociedad.

La forma no es más que una tipificación elaborada a partir de datos observables, hechos a base de descripciones, sin que quepa sospechar lo observado o descrito ni criticarlo. Esto obliga a una conversión de la mirada: apreciar cada cosa a partir de su propia lógica, a partir de su coherencia oculta, y no a partir de un juicio exterior que dicta lo que debe ser. El formismo da cuenta de la autoproducción (auto-poiesis) permanente. ${ }^{42}$

39 Maffesoli, El tiempo de las tribus, 91.

40 Este término, en un principio, fue acuñado por George Simmel y desarrollado por Michel Maffesoli.

41 Maffesoli, En el crisol de las apariencias, 103.

42 Ibíd., 110. 
La forma es lo que diferencia un fenómeno social de otro. Hay formas parecidas pero no idénticas.En este caso, desde fuera, parece que "todos bailan igualito"; sin embargo, sus actores saben que cada persona tiene un estilo propio, es decir, las formas se parecen en algún sentido y se diferencian en otro, esos significantes adquieren significados que al bailar se conjugan sensaciones diferentes, ritmos, acoples, goces, ese es el sabor del baile "a este conjunto es al que llamo formismo, es este conjunto el que, en sentido estricto, puede caracterizar a la cultura en un momento dado." 43 Sin embargo, no se debe confundir la forma con el estilo.La forma en la que los sujetos habitan Lavoe no siempre tiene que ver con el baile; forma una parte importante, ya que es una salsoteca y su pista de baile es el escenario, pero el existir y sentir desde el interior del lugar no es el mismo. Se trata de explicar que no solo se disfruta cuando se baila, se conoce gente nueva todos los días, se conversa, se toca instrumentos, se observa bailar y disfrutar a los otros, tratar de seguir los pasos y una práctica muy interesante es "robar pasos de baile": "Yo me robo todos los pasos de baile que puedo, solo me siento a mirar a las bailarinas que me gustan; pocos lo aceptamos, pero todos lo hacemos y esa es la dinámica". ${ }^{44}$

Aunque sean los mismos pasos, cada persona tiene una energía diferente, un olor distinto e impone su estilo a la hora de bailar, yo tengo ya elegidas mis parejas, ya sé quién me llena cuando bailo, yo improviso bastante y necesito parejas que me sigan, se dejen llevar y que la gocen como yo, busco sabor, ese sabor del baile que solo saben y sienten los que bailamos, sudamos y sentimos esa vibra. Cuando voy a Lavoe, voy a bailar, no a enseñar. Soy un bailador, voy a disfrutar de esa química y conexión con las demás personas. ${ }^{45}$

Por otro lado, Schechner plantea que "la mayoría de gente vive en una tensión entre la aceptación y la rebelión. Las actividades de la vida pública —a veces tranquilas, a veces llenas de agitación, a veces visibles, a veces enmascaradas-son representaciones colectivas. Estas actividades intentan encontrar o crear planos de entendimiento común". ${ }^{46 S}$ Son "formas" de juntarse, es decir, la salsa también es una

43 Ibíd., 111.

44 Anónima, la entrevistada pidió no revelar su identidad, entrevista realizada el 10 de junio de 2015.

45 Leandro Villacís, salsero, entrevista realizada el 7 de febrero de 2015.

46 Schechner, Estudios de la representación, 59. 
forma del "estar juntos". En definitiva, "el formismo hace pasar de una 'lógica de la identidad'a una 'lógicade la identificación'". 47

Desde esta entrada que enfatiza lo estético, se entiende que en el mundo contemporáneo, el gusto y el sentir se vuelven ideología y eso es precisamente lo que permite mantener enganchados a los actores dentro de este espacio cultural de carácter industrial. Ese sentir tiene que ver con estéticas del cuerpo, del lugar, estéticas imaginadas. Finalmente, las estéticas están vinculadas con la ideología, es decir, lo ideológico que se vuelve más una cosa "del sentir". Se trata de dar cuenta del engranaje interno del capital simbólico. Mario Perniola explica que:

La sustitución de la ideología por la sensología ${ }^{48}$ produce una genuina subordinación del pensar al sentir, capaz de conferir a los pensamientos y a los actos una dimensión real que ya no pueden alcanzar por sí solos [...]. Nuestra época reclama y pretende más: conseguir el extrañamiento del sentir y situarlo en el exterior para que sea de algún modo independiente, social y colectivo. En efecto, la realidad no tiene nada de racional y práctico, ha pasado a ser esencialmente estética, está impregnada de sensibilidad y afectividad. ${ }^{49}$

Dentro del ambiente de Salsoteca Lavoe existen personajes, es decir, clientes frecuentes que prácticamente forman parte del imaginario del lugar y que siempre se eligen como pareja. "Cuando se trata de una buena timba, prefiero bailarla con la Ale o la Gaby. Son sabrosas para bailar, cada una tiene un estilo propio y único y a ninguna le repito los giros, hacerle una figura distinta a cada una es como hacerle un homenaje a la autenticidad, porque yo lo siento así, yo siempre bailo con el corazón, la clave me sale desde el fondo del ser". 50 Este testimonio denota cómo se exteriorizan los sentimientos a la hora de bailar y de elegir cómo y con quién se baila lo que se baila.Así se explica la estética en la salsa, desde el mundo afectivo y sensible, desde esta construcción de un mundo simbólico.

47 Maffesoli, En el crisol de las apariencias, 106.

48 Según Perniola, la sensología es el punto de encuentro entre los aspectos emocional y racional.

49 Mario Perniola, Del sentir (Valencia: Pre textos, 2008), 38-40.

50 AlexiñoMedranda, bailador, entrevista realizada el1 de mayo de 2015. 


\section{La salsa y sus voces: entre el bailarín, el bailador y el "no salsero"}

Describir las lógicas y las sensibilidades inherentes a las prácticas salseras del baile en la SalsotecaLavoe como parte de la etnografía, precisa hacer una diferenciación que se considera clave para entender las formas de bailar. Por un lado, se menciona a los salseros que bailan sin haber aprendido con clases particulares y con fines de competencia, sino que lo hicieron en los antiguos bares de la ciudad como el Mayo 68 o el Seseribó. En el mundo salsero se los conoce como "bailadorxs" o "callejerxs".

Sin embargo, existe otro grupo de salseros que, por su inclinación hacia la salsa como show y espectáculo, han aprendido a bailar en academias y escuelas, y su aprendizaje apunta básicamente a participar en eventos de competencia, ante un jurado calificador, en torneos nacionales e internacionales. Pero eso no los hace menos salseros o eso no significa que sientan menos la salsa que los otros, son bailarines de coreografía, construyen su entrenamiento para un escenario, presentan un espectáculo para un público, bailan diferentes estilos de competencia; estos actores son "bailarines".

Ulloa argumenta que "el bailarín se torna un bailador cuando participa de la rumba". En este caso, hablamos de bailadores porque son quienes bailan por placer en un lugar de socialidad y encuentro, como es el caso de Salsoteca Lavoe, ellos lo llaman "baile social". En esta salsoteca, todos son bailadores, aunque se distinga claramente sus inclinaciones de baile. Este es el espacio para los bailarines y también para los que no lo son, pero gustan de la salsa aunque no bailen con técnica.

En este sentido, Ulloa hace referencia a la "representación mimética", es decir, la imitación "que está en el origen de la danza así como está en origen del lenguaje verbal y de todas las artes en general". ${ }^{1}$ Por ejemplo, las coreografías pueden entenderse como el encuentro entre los cuerpos dentro de una sincronización o armonía, en una suerte de espejo o semejanza; se imita la igualdad y la coordinación de movimientos en pareja durante la actuación y este baile coreografiado se da más 
precisamente entre los bailarines, es decir, entre aquellos que aprendieron a bailar salsa en una academia. En este caso, se escenifica un baile educado, entrenado y practicado, puesto que, en los espacios sociales, se trata de mostrar lo aprendido, pero también hay espacio para el error y la improvisación; esa es la dinámica, en solitario, en parejas, en tríos o en grupos.

Sin embargo, los salseros "callejeros" discrepan o por lo menos no disfrutan mucho de los salseros de academia; no conciben que algo que ellos consideran muy del mundo afectivo se aprenda en una academia, consideran que "Ios sentimientos no se aprenden en clases":

Soy "callejera", jamás he tenido una clase de salsa, bailo cantando las letras de las canciones, no contando los pasos de baile. No me gusta que me saquen a bailar porque yo elijo con quien bailo, ya tengo mis parejas preferidas para cada tipo de salsa, yo sé con quién bailo las cubanas y con quién las descargas, cada uno tiene su encanto y su sabor. Yo siento el sabor del baile en cada pareja que elijo y no me importa si es o no de escuela. 52

Este tipo de apreciaciones en cuanto al baile apela a un sentir, cada uno de los sujetos se "enamora" de un estilo, de un sabor. Cuando se baila, es muy importante la conexión con la otra persona, no es solo un acto de llevar y dejarse llevar, tampoco es solamente de género (el hombre lleva y la mujer se deja llevar, existen mujeres que llevan muy bien, bailan de los dos roles sin problema y con el mismo goce), se trata de una construcción en relación con la alteridad, cómo se visualizan y construyen frente al otro y con el otro; asimismo, cómo conciben al otro a la hora de bailar o interactuar y esto no tiene nada que ver con pertenecer o no a alguna escuela.

Ulloa plantea la metáfora del baile para explicar las interacciones en tránsito, es decir, una misma persona puede ser bailarín y bailador a la vez, puede bailar de hombre o de mujer a la vez o las dos en tránsito (aquella chica que aprendió a bailar para competir en concursos, pero también puede bailar sin competencia, por puro placer y sin público, sola o acompañada con hombres o con mujeres, solo bailar por sentir la música para su propio goce y placer). "Me gusta bailar con la Kary, ella lleva 
mejor que muchos de los hombres con los que bailo" 53 . Estos encuentros fugaces que, por más cortos que sean, proponen vinculación, apoyados en un soporte corporal que genera "oposiciones y paralelos, simetrías y rupturas, está hecho de reciprocidades con las cosas y con los otros cuerpos". 54

En este escenario, el que baila construye su espacio e identificación mediante la apropiación de la música al representarla en el espacio social ante los demás. Se trata de mirar (desde diferentes lugares y autores) las formas escénicas. Ya sea como entretenimiento o "entrenamiento" cotidiano, se abren espacios que posibilitan, incluso, una relación lúdica entre distintas generaciones. Estas dos diferentes tendencias de salseros habitan los mismos espacios de baile, y aunque no siempre están de acuerdo los unos con los otros en cuanto a esos estilos que practican, en la pista, se entienden, se respetan y construyen un performance y el ambiente para el entretenimiento.

Por último hay que decir que, en este escenario, existe y cohabita un tercero, "el no salsero", es decir, la personas que no entiende los códigos que se manejan en su interior (como beber en plena pista, cosa que está totalmente prohibida), ni las lógicas del baile pero que son atraídos por estos espacios y por eso forman parte constitutiva y fundamental del negocio:

El "no salsero" también es parte de la dinámica del negocio, llega a consumir y a ver, es el "novelero", existe en todo el mundo.Por desgracia, son mayoría y hay que educarlos o evitarlos. Educarlos en el sentido de que hay que poner letreros o indicarles que no pueden beber en la pista, ya que es una pista de baile profesional, pero los pisotones y los codazos porque no respetan la línea de baile de los demás son inevitables. Sin embargo, entre los conocidos del baile mantenemos una armonía y un ambiente festivo, cuando hay menos "no salseros", para mí es mejor porque todos entendemos cómo funciona nuestro espacio, respetamos y valoramos a los demás. ${ }^{55}$

Ante ello, Manuel Delgado propone un análisis social de lo festivo y argumenta que "la condensación festiva lanza una malla sobre el espacio público, que lo convierte en escenario sobre el que se representa el gran drama de lo social, todo el

53 Anónima, la entrevistada pidió que no se revele su identidad, entrevista realizada el 10 de junio de 2015.

54 Delgado, Disoluciones urbanas, 128.

55 Billy Gills, salsero, entrevista realizada el 19 de febrero de 2015. 
hecho de solidaridades y de encontronazos entre quienes, siendo muchas veces incompatibles, se necesitan". 56

De hecho, los estilos de baile también son producto de la globalización de la salsa, también es una moda. Maffesoli sostiene que "cada época tiene sus ideas obsesivas". Aquí se manifiestan mediante el cuerpo, se encuentran pero también discrepan, bailan y se comunican desde su propio lugar, "le ponen su huella". En la pista de Salsoteca Lavoe, todos se comunican y se toleran, cada actor asume su rol y se apropia del espacio y del cuerpo, se piensa y se siente perteneciente a un grupo social que coincide con sus prácticas y con sus frecuencias ya que así como es un mundo sonoro, también, es donde prima la imagen de los movimientos en un ambiente lúdico-festivo, flujo de baile, coordinación, interacción, armonía y básicamente, comunicación.

Según el autor, la fiesta es el reflejo social de cómo es una sociedad por dentro. Mediante la fiesta, se visibilizan los segmentos que la articulan y conforman. El baile también se refiere al espectáculo. Al respecto, Maffesoli lo entiende como "la profundidad de la superficie", relacionado con el cómo se construye la sociedad contemporánea desde la imagen y afirma que vivimos el "mundo de lo visible" que existe y produce sentidos. Este tiene importancia en las construcciones simbólicas de la sociedad, "el cuerpo en espectáculo es causa y efecto de comunicación".57

Dentro de Salsoteca Lavoe, se escenifica noche a noche un ambiente festivo, de interacción, de goces, al que las personas asisten, entre otras cosas, para ver y ser vistas, para socializar y estar en contacto con otros. Hace referencia a la multiplicidad de expresiones a las que se tiene acceso mediante el cuerpo. Justamente de eso se trata la negociación: "Se negocia y se renegocia gestualmente el orden de relaciones, con el escenario, con los objetos y los accidentes que lo caracterizan". 58

Este trabajo es un intento por acercarse a las estéticas y los sentidos surgidos de las formas que adoptan los cuerpos en movimiento y cómo estas forman la base

56 Delgado, Disoluciones urbanas, 157

57 Maffesoli, En el crisol de las apariencias, 251.

58 Manuel Delgado, "Bailar pegados", El cor de les aparences, 11 de agosto de 2016, http://manueldelgadoruiz.blogspot.com.es/2012/08/el-bailar-agarrado-como-forma-de.html. 
de las diversas identidades grupales entre los participantes del performance salsero en el lugar estudiado. Se ha tratado de recoger las percepciones de sus actores para entender los sentidos de pertenencia dentro de un contexto cultural específico. Estos son los hallazgos que arroja la investigación sobre las interacciones, socialidades y sensibilidades que deben leerse como constitutivas del mundo simbólico construido y vuelto a construir alrededor del baile y el consumo musical, así como del universo simbólico que se escenifica y es practicado en una salsoteca.

\section{Conclusiones}

El interés académico de este trabajo apuntó a indagar acerca de cómo las interacciones y el uso de ciertos espacios relacionados con las corporalidades y las representaciones sociales configuradas alrededor de las prácticas del baile salsero construyen procesos de socialidad y encuentro, así como genera procesos de identificación personal y colectiva. Se buscó comprender la salsa como un conjunto de géneros musicales y expresividades dancísticas que generan lugares de comunicación en las noches urbanas.

Por otro lado, enfocando la cuestión de los roles de género, se encontró que Salsoteca Lavoe es un lugar que rompe los tradicionales roles sociales asignados a hombres y mujeres. En esta salsoteca, es común ver bailar dos hombres, dos mujeres, tríos (mixtos), grupos (ruedas de casino), sin ningún tipo de elemento represivo o alguna clase de estigma o etiqueta, lo que lleva a la construcción de nuevas representaciones y prácticas alternativas de género desde el baile. 


\section{Bibliografía}

Delgado, Manuel. Disoluciones urbanas: Procesosidentitarios y espacio público. Medellín: Universidad de Antioquia, Facultad de Ciencias Humanas, 2002.

- "Bailar pegados", El cor de les aparences, 11 de agosto de 2016, http://manueldelgadorviz.blogspot.com.es/2012/08/el-bailar-agarradocomo-forma-de.html.

Galindo Cáceres, Jesús, coord. Técnicas de investigación en sociedad, cultura y comunicación. CDMX: Addison Wesley Longman, 1998.

Fischer-Lichte, Érika. Estética de lo performativo. Madrid: Abada, 2011.

Hall, Stuart. "The Work of Representation". En Representation: Cultural Representations and Signifying Practices, editado por Stuart Hall, 13-74. Londres: SagePublications, 1997. http://fba.unlp.edu.ar/lenguajemm/?wpfb_dl=31

Le Breton, David. El sabor del mundo: Una antropología de los sentidos. Buenos Aires: Nueva Visión, 2007.

López, Rubén "La salsa en disputa: Apropiaciones, propiedad intelectual, origen e identidad". Etno-folk. Revista de Etnomusicología 14-15 (2009): 522-41.

Maffesoli, Michel. El tiempo de las tribus. CDMX: Siglo XXI, 2004.

- El nomadismo: Vagabundeos iniciáticos. CDMX: FCE, 2004.

-. En el crisol de las apariencias. CDMX: Siglo XXI, 2007.

Martín Barbero, Jesús. "Tecnicidades, identidades, alteridades: Desubicaciones y opacidades de la comunicación en el nuevo siglo". Diálogos de la Comunicación 64 (2002): 9-24.

Pedraza, Zandra. En cuerpo y alma: Visiones del progreso y de la felicidad. Bogotá: Universidad de los Andes, 1999.

Perniola, Mario.Del sentir.Valencia: Pre textos, 2008.

Schechner, Richard.Performance Theory.Londres: Routledge, 2004.

- Estudios de la representación: una introducción. CDMX: FCE, 2012.

Ulloa, Alejandro. El baile: un lenguaje del cuerpo. Cali: Secretaria de Cultura y Turismo, Gobernación del Valle del Cauca, 2003. 